\title{
INDUÇÃO DE RETINITE POR CITOMEGALOVÍRUS HUMANO (HCMV), EM COELHOS IMUNOSSUPRIMIDOS
}

\author{
RETINITIS INDUCTION BY HUMAN CYTOMEGALOVIRUS IN IMUNOSSUPRESSED RABBITS
}

Fabrizio L. Mascaro da Silva'; josé Fernando C. Figueiredo²; Luiz Tadeu M. Figueiredo; Cláudia C. Sauaia ${ }^{4}$; Erasmo Romão ${ }^{5}$ Maria de Lourdes Veronese Rodrigues ${ }^{5}$

\begin{abstract}
${ }^{1}$ Bolsista PIBIC/CNPq. Doutorando; ${ }^{2}$ Docente Divisão de Moléstias Infecciosas e Tropicais; ${ }^{3}$ Docente. Unidade Multidisciplinar de Pesquisa em Virologia. Departamento de Clínica Médica; ${ }^{4}$ Mestre em Oftalmologia; ${ }^{5}$ Docente do Departamento de Oftalmologia e Otorrinolaringologia. Faculdade de Medicina de Ribeirão Preto-USP.

Correspondência: Fabrizio Leon Mascaro da Silva. Departamento de Oftalmologia e Otorrinolaringologia. Faculdade de Medicina de Ribeirão Preto-USP. Av. Bandeirantes, 3900. CEP 14049-900 Ribeirão Preto, São Paulo, Brasil. Fax (16)602-2860.
\end{abstract}

SILVA FLM; FIGUEIREDO JFC; FIGUEIREDO LTM; SAUAIA CC; ROMÃO E \& RODRIGUES MLV. Indução de retinite por citomegalovírus humano (HCMV), em coelhos imunossuprimidos. Medicina, Ribeirão Preto, 33: 117122, abr.jun. 2000.

RESUMO: A procura por novos esquemas terapêuticos para a retinite por HCMV levou pesquisadores à busca de um modelo animal para o estudo desta infecção. Em estudo anterior, não conseguimos nível adequado de imunossupressão com associação de Azathioprina e Prednisona em coelhos. Assim, optamos por utilizar a Ciclofosfamida em cinco coelhos da raça New Zealand, e injetamos HCMV no vítreo de ambos os olhos de cada um deles, em diferentes etapas do protocolo de imunossupressão. O período de seguimento foi de até 112 dias, avaliando-se alterações sistêmicas (peso, hemograma) e alterações oculares (através de oftalmoscopia binocular indireta e retinografia). Após o sacrifício dos animais, pesquisaram-se antígenos de HCMV em vítreo e retina. Encontrou-se importante perda de peso, hemograma não compatível com os sinais de imunossupressão, lesões retinianas e alterações vítreas inespecíficas (exsudatos e vitreíte com involução espontânea). Não foram detectados antígenos de HCMV nos Inprints de retinas e vítreos dos coelhos sacrificados. Desse modo, concluiu-se que, também com esse novo esquema de imunossupressão, o HCMV causa inflamação intra-ocular inespecífica. Portanto, a inoculação do HCMV, em coelhos, não determina modelo experimental para a retinite pelo CMV.

UNITERMOS: Retinite por Citomegalovírus. Imunossupressão. Ciclofosfamida. Coelhos.

\section{1- INTRODUÇÃO}

A pesquisa de um modelo animal para o estudo da infecção retiniana por Citomegalovírus humano (HCMV) tornou-se de fundamental importância após o surgimento da Síndrome da Imunodeficiência Adquirida (aids $)^{(1 / 4)}$. O aumento do número de casos e a conseqüência final dessa infecção ocular (cegueira) motivou a procura por novos esquemas terapêuticos ${ }^{(5)}$. A realização de pesquisas para este fim trouxe a ne- cessidade da obtenção de um modelo animal, que está sendo estudado por vários pesquisadores ${ }^{(6 / 9)}$.

Na FMRP-USP, estudou-se a indução de retinite por HCMV em coelhos imunocompetentes e imunossuprimidos ${ }^{(8,9)}$. Houve o aparecimento de resposta vitreoretiniana (lesões retinianas brancas, turvação do vítreo, fibrose sobre o nervo óptico) nos dois grupos de animais e, também, em grupo-controle (coelhos inoculados com meio de cultura sem CMV). A gravidade das lesões guardou relação com a dose do CMV uti- 
lizado, sendo mais evidente com inóculo contendo $10^{2,5} \mathrm{TCID}_{50}$ por ml. Detectou-se o CMV no exame imunoistoquímico das retinas dos coelhos imunocompetentes, mas não no das retinas dos coelhos imunossuprimidos. Foi observado que as lesões vítreoretinianas foram autolimitadas, regredindo espontaneamente em todos os grupos de coelhos estudados. Concluiu-se, a partir das observações, que a inoculação de CMV humano, em coelhos, causa reação inflamatória inespecífica e, apesar da conclusão, foi questionado se a intensidade de imunossupressão induzida pelo esquema empregado foi suficiente para o desenvolvimento da retinite. Assim, julgamos necessário realizar novo estudo com diferente esquema de imunossupressão.

\section{2- MATERIAIS E MÉTODOS}

Foram estudados cinco coelhos da raça New Zealand, do sexo feminino, com peso aproximado de $3 \mathrm{~kg}$, que receberam Ciclofosfamida ${ }^{(10)}$ na dose $65 \mathrm{mg} / \mathrm{kg}$ de peso, por via EV e $\mathrm{IM}^{(11,12,13)}$, com um intervalo de seis dias entre as injeções ${ }^{(11)}$. O esquema acima foi administrado de maneira continuada durante todo o período de acompanhamento clínico e oftalmológico dos animais, completando o total de 19 injeções. Os olhos direitos receberam a dose $10^{2,5}$ TCID $_{50}$ de HCMV, diluída em meio de cultura, contendo fibroblastos humanos, no $42^{\circ}$ dia de imunossupressão medicamentosa. Os olhos esquerdos foram poupados e utilizados como controles, inicialmente; no entanto, no $78^{\circ}$ dia de imunossupressão medicamentosa, receberam a dose $10^{2,5}$ TCID $_{100}$ de HCMV. A inoculação do CMV foi feita por via intravítrea, através de agulha de Insulina, a 5-6 mm do limbo. A inoculação foi feita em dose única.

\subsection{Preparo e cálculo do inóculo}

Diluições decimais e seriadas, até 1:1000, da amostra de CMV cepa AD169 (estirpe de CMV humano, adaptada ao uso de laboratório) foram inoculadas, em quadruplicata, $10 \mu \mathrm{L}$ por orifício, numa microplaca de 96 orifícios, contendo monocamadas de fibroblastos humanos. As colônias foram observadas em microscópio invertido no $15^{\circ}$ dia pós-inoculação, quando se determinaram os orifícios em que as monocamadas apresentaram efeito citopatogênico característico. Com base na leitura do teste, calculouse o título viral em dose infectante para $50 \%$ e $100 \%$ (OD e OE, respectivamente) das culturas celulares

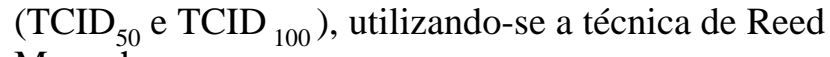
Muench.

\subsection{Critérios de avaliação}

Os critérios de avaliação sobre a evolução dos coelhos foram os seguintes: Peso, aferido diariamente; Alterações gerais, como queda de pelos, diminuição do apetite, diarréia, óbito, etc; Hemograma, exames que começaram a ser realizados na quarta semana (após a quinta injeção); foram realizados, imediatamente antes de cada injeção subseqüente, a fim de se avaliar, imediatamente, o nível de imunossupressão nos coelhos; Oftalmoscopia binocular indireta, no $4^{\circ}$ dia após a inoculação do CMV intravítreo e nos intervalos de uma semana, a partir da primeira observação; e Retinografia, realizada quando a oftalmoscopia binocular indireta evidenciava alguma alteração retiniana ou vítrea.

\subsection{Caracterização das lesões retinianas nos animais}

No final do período de observação, os animais foram sacrificados e suas retinas extraídas para exame virológico com o olho in situ. Logo após a retirada, foram feitos inprints do tecido retiniano em lâminas de microscopia que, a seguir, foram secas e fixadas por 15 minutos, em acetona gelada. Os locais sobre as lâminas, contendo os tecidos (spots), foram identificados com esmalte de unhas e, posteriormente, foram submetidos a teste de imunofluorescência direta para identificação de antígenos virais. Para tal, acrescentaram-se, sobre os spots, $50 \mu \mathrm{L}$ de anticorpo monoclonal específico para CMV, conjugado a fluoresceína e diluído em solução azul de Evans (FITC / Labeled Monoclonal Ab with Evans Blue Counterstain, Baxter Diagnostic Inc., Issaqual, WA, USA). As lâminas foram incubadas por 30 minutos a $37^{\circ} \mathrm{Ce}$, a seguir, lavadas com PBS por 10 minutos e com água destilada por um minuto. Em sequiência, as lâminas foram secas e montadas com lamínulas, utilizando-se glicerina na interface, observadas e fotografadas, utilizando-se microscópio de fluoresceína com lâmpada de mercúrio (Zeiss, Alemanha). Após a retirada dos olhos, foram feitos, também, esfregaços do humor vítreo sobre lâminas de microscopia que, a seguir, foram processados da mesma forma que os inprints de retina.

\section{3- RESULTADOS}

O período de observação dos animais foi de até 112 dias, totalizando 19 injeções imunossupressoras. Os coelhos 3 e 4 foram a óbito no D70 (três dias após a 12a injeção) e D82 (três dias após a 14a injeção) de imunossupressão, respectivamente. O coelho 1 foi sacrificado no D106 e os coelhos 2 e 5 sacrificados no D112 de Imunossupressão. 


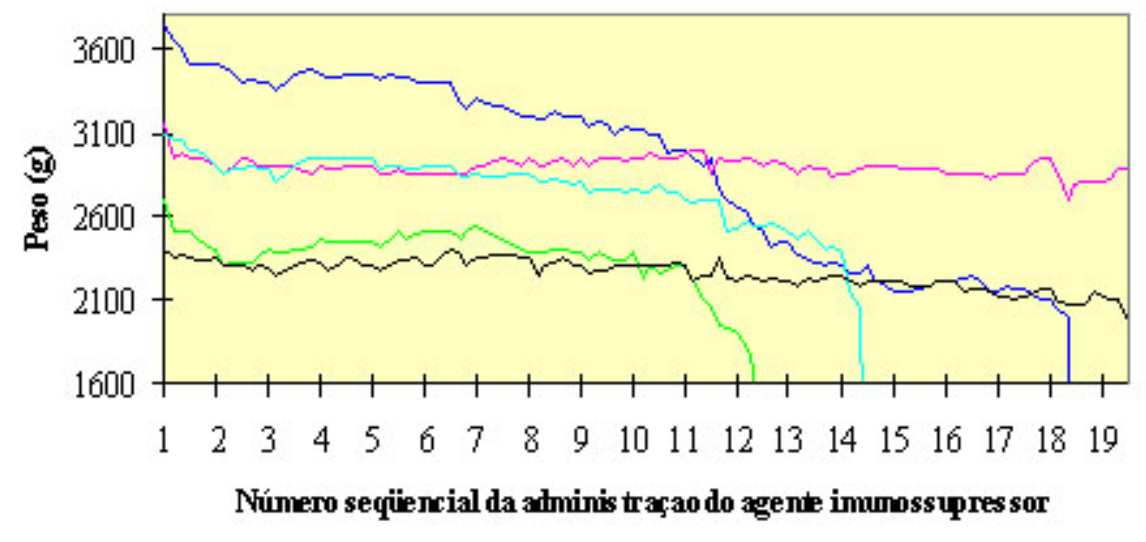

Figura 1 - Variação do peso (em gramas) dos coelhos estudados no decorrer do experimento.

Os parâmetros hematológicos ${ }^{(14)}$ não mostraram variação significativa com o decorrer do experimento.

A oftalmoscopia binocular indireta foi realizada semanalmente e as alterações, observadas no fundo de olho dos animais, e sua evolução são descritas nas Tabelas I (OD) e II (OE).

Conforme mostrado, as alterações observadas foram inespecíficas e apresentaram involução espon-

As alterações gerais, observadas nos animais, foram: coriza e diarréia (de caráter limitado), e, principalmente, queda de pelos e perda de peso. A via de administração foi alterada a partir da sétima injeção imunossupressora, de endovenosa para intramuscular, devido a necrose ou esclerose das veias utilizadas para a injeção. tânea. As retinografias mostram a imagem de um fundo de olho normal (Figura 2) e uma vitreíte intensa, impedindo a focalização da retina (Figura 3), observada nos coelhos 4 e 5 (em diferentes graus), tratando-se de reação inespecífica.

Não foram detectados antígenos de CMV nos Inprints de retinas e vítreos dos coelhos.

\begin{tabular}{|c|c|c|c|c|c|}
\hline $\begin{array}{l}\text { Dias após a } \\
\text { inoculação }\end{array}$ & Coelho 1 & Coelho 2 & Coelho 3 & Coelho 4 & Coelho 5 \\
\hline 4 & $\begin{array}{l}\text { Fundo de olho } \\
\text { normal }\end{array}$ & $\begin{array}{l}\text { Fundo de } \\
\text { olho normal }\end{array}$ & $\begin{array}{l}\text { Fundo de olho } \\
\text { normal }\end{array}$ & $\begin{array}{l}\text { Fundo de olho } \\
\text { normal }\end{array}$ & $\begin{array}{l}\text { Fundo de olho } \\
\text { normal }\end{array}$ \\
\hline 11 & $\begin{array}{l}\text { Exsudato al- } \\
\text { godonoso, na } \\
\text { parte superior } \\
\text { do disco }\end{array}$ & $\begin{array}{l}\text { Exsudato al- } \\
\text { godonoso, } \\
\text { próximo ao } \\
\text { disco (forma } \\
\text { umbilicada) }\end{array}$ & $\begin{array}{l}\text { Exsudato em } \\
\text { semi-lua, no } 1 / 3 \\
\text { posterior do } \\
\text { vítreo, proje- } \\
\text { tando-se sobre } \\
\text { o disco }\end{array}$ & $\begin{array}{l}\text { Vítreo turvo, com } \\
\text { estrutura em } \\
\text { forma de cisto } \\
\text { (bolha?) }\end{array}$ & $\begin{array}{l}\text { Fundo de olho } \\
\text { normal }\end{array}$ \\
\hline 18 & $\begin{array}{l}\text { Diminuição do } \\
\text { exsudato. }\end{array}$ & $\begin{array}{l}\text { Fundo de } \\
\text { olho normal }\end{array}$ & $\begin{array}{l}\text { Exsudato não } \\
\text { visualizado, } \\
\text { apenas região } \\
\text { circular com } \\
\text { leve pigmen- } \\
\text { tação ao redor }\end{array}$ & $\begin{array}{l}\text { Vítreo com } \\
\text { áreas de opaci- } \\
\text { ficação e ima- } \\
\text { gem sugestiva } \\
\text { de cisto. Fundo } \\
\text { normal. }\end{array}$ & $\begin{array}{l}\text { Fundo de olho } \\
\text { visível, mas } \\
\text { embaçado } \\
\text { (Reação Ví- } \\
\text { trea ?) }\end{array}$ \\
\hline 25 & $\begin{array}{l}\text { Fundo de olho } \\
\text { normal }\end{array}$ & $\begin{array}{l}\text { Fundo de } \\
\text { olho normal }\end{array}$ & $\begin{array}{l}\text { Fundo de olho } \\
\text { normal }\end{array}$ & $\begin{array}{l}\text { Sem alterações } \\
\text { em relação ao } \\
\text { exame anterior }\end{array}$ & $\begin{array}{l}\text { Sem alterações } \\
\text { em relação ao } \\
\text { exame anterior }\end{array}$ \\
\hline 32 & $\begin{array}{l}\text { Fundo de olho } \\
\text { normal }\end{array}$ & $\begin{array}{l}\text { Fundo de } \\
\text { olho normal }\end{array}$ & $\begin{array}{l}\text { Ó } \\
\text { B } \\
1 \\
T \\
0\end{array}$ & $\begin{array}{l}\text { Exsudato vítreo } \\
\text { se organizando. } \\
\text { Retina sem } \\
\text { alterações }\end{array}$ & $\begin{array}{l}\text { Vítreo turvo } \\
\text { com exsuda- } \\
\text { ção no vítreo. } \\
\text { Retina sem al- } \\
\text { terações. }\end{array}$ \\
\hline
\end{tabular}




\begin{tabular}{|c|c|c|c|c|c|}
\hline $\begin{array}{l}\text { Dias após a } \\
\text { inoculação }\end{array}$ & Coelho 1 & Coelho 2 & Coelho 3 & Coelho 4 & Coelho 5 \\
\hline 4 & $\begin{array}{l}\text { Fundo de olho } \\
\text { normal }\end{array}$ & $\begin{array}{l}\text { Vítreo turvo, } \\
\text { retina sem } \\
\text { alterações }\end{array}$ & $\begin{array}{l}\text { Ó } \\
\mathrm{B}\end{array}$ & $\begin{array}{l}\text { Ó } \\
\text { B }\end{array}$ & $\begin{array}{l}\text { Vitreo turvo, } \\
\text { retina sem } \\
\text { alterações }\end{array}$ \\
\hline 11 & $\begin{array}{l}\text { Fundo de olho } \\
\text { normal }\end{array}$ & Vitreíte (3+) & I & I & Vitreíte (4+) \\
\hline 18 & $\begin{array}{l}\text { Fundo de olho } \\
\text { normal }\end{array}$ & Vitreíte $(2+)$ & $\mathrm{T}$ & $T$ & Vitreíte (3+) \\
\hline 25 & $\begin{array}{l}\text { Fundo de olho } \\
\text { normal }\end{array}$ & $\begin{array}{l}\text { Vitreíte }(1+) \\
\text { Retina sem } \\
\text { alteração. }\end{array}$ & $\mathrm{O}$ & $\mathrm{O}$ & Vitreíte (3+) \\
\hline
\end{tabular}

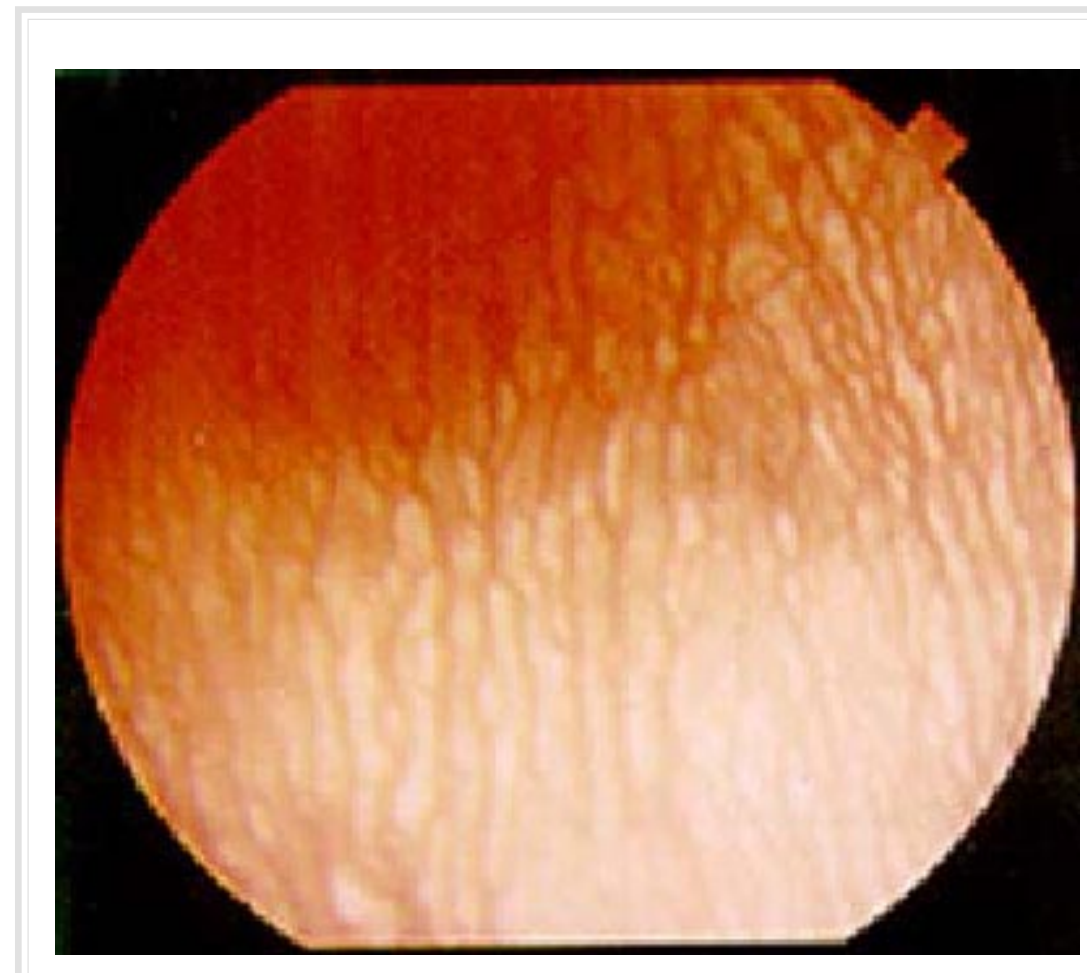

Figura 2 - Fundo de olho normal de coelho.

Houve progressão da doença para uma vitreíte mais severa, com envolvimento de camadas retinianas externas em algumas áreas, destruição retiniana, edema de coróide e áreas de congestão. O HCMV foi recuperado de cultura de células coriorretinianas, em títulos variando de $10^{4}$ a $10^{5} \mathrm{pfu}$, durante o pico da doença. Antígenos de HCMV foram detectados por imunofluorescência, na retina, dois a quatro dias após a inoculação. Os autores concluíram, a partir dessas observações, que o modelo de retinite pelo CMV poderia ser utilizado para estudos experimentais referentes a retinite pelo HCMV.

Tatebayashi $^{(6)}$ et. al.,1995, realizaram, também, um estudo para avaliação do modelo experimental, em coelhos, de retininite por HCMV, realizando injeção intravítrea e pré-retiniana de HCMV em olhos de coelhos. Vitreíte, congestão do nervo óptico, múltiplos

\section{4- DISCUSSÃO E CONCLUSÕES}

Dunkel et al. ${ }^{(7)}$, 1993, descreveram um modelo experimental de retinite por HCMV, em coelhos, fazendo injeção intravítrea de $10^{5}$ pfu do HCMV AD169 em coelhos. Vitreítes e áreas focais de infiltrado de células imunológicas foram vistas nas camadas retinianas internas, dois a quatro dias após a inoculação. infiltrados brancos e pequenos, no vítreo ou na superfície retiniana, e descolamento de retina foram observados. A histopatologia mostrou a presença de infiltrado de células inflamatórias no vítreo, nervo óptico e na superfície retiniana externa. A estrutura retiniana foi preservada, exceto pelas alterações nas áreas do descolamento de retina. Não foram vistas áreas de necrose ou destruição da retina. A imunoistoquímica 


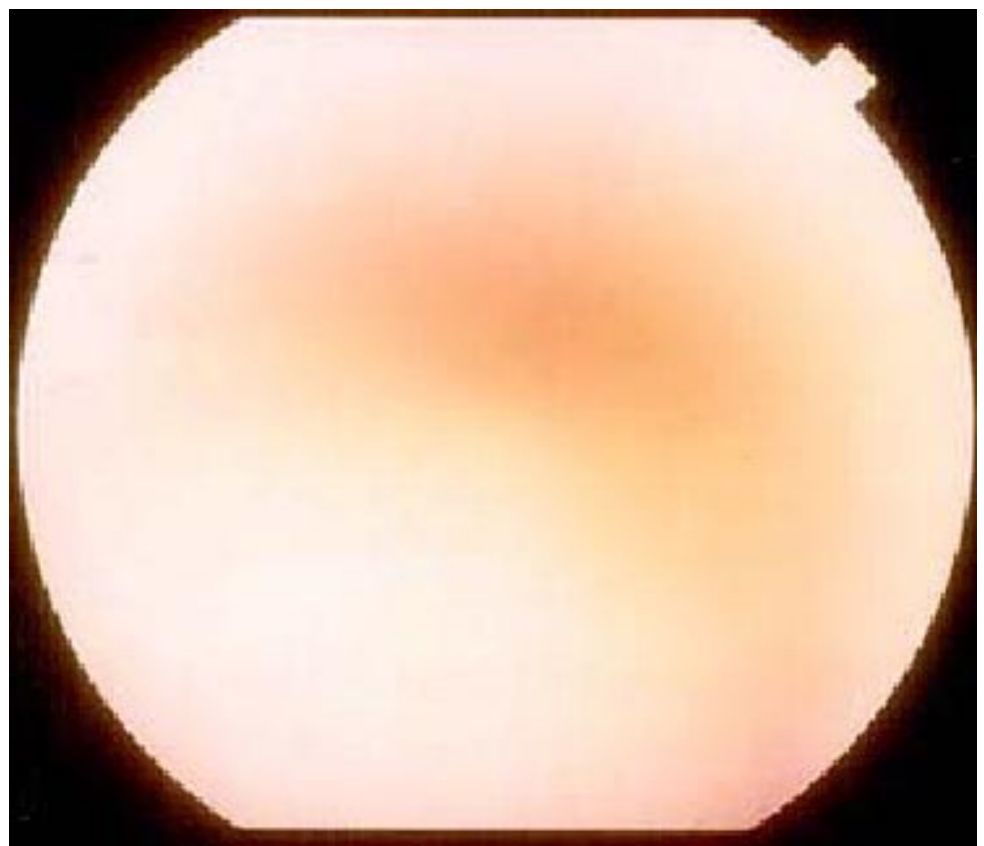

Figura 3 - Fundo de olho, mostrando intensa reação vítrea, impedindo a visualização da retina. cífica, sem evidências de infecção, sendo o modelo considerado não apropriado paro o estudo da retinite por HCMV.

Laycok $^{(15)}$ et al, em 1997 , descreveram um modelo experimental de retinite por HCMV, em ratos, em que a retina humana é implantada na câmara anterior de olhos de ratos e, então, é inoculado HCMV no mesmo local. Foi observado que ocorreu replicação do HCMV na retina humana.

Esses trabalhos, que trazem resultados positivos, mostram alguns inconvenientes como: curto período de observação ${ }^{(7)}$ e dificuldade técnica na avaliação da doença ${ }^{(15)}$.

O presente trabalho mostrou que não foi constatada infecção retiniana por HCMV, nos coelhos examinados, como também não foram detectados antígenos de CMV nos Inprints de retinas e vítreos dos coelhos. Isso nos leva a concluir que, não mostrou evidências de infecção pelo CMV. A inoculação do meio de cultura, contendo soro de bovino fetal, causou reação similar aos inóculos que continham o vírus. Os autores concluíram, então, que a inoculação do HCMV no vítreo e retina, em olhos de coelhos, causaram uma reação inflamatória não espe- mesmo com o uso de novo esquema de imunossupressão e com o uso de diferentes inóculos, a injeção intraocular de CMV humano causa lesões retinianas e alterações vítreas inespecíficas, em coelhos, reforçando a característica de que o CMV humano seja altamente específico da espécie.

SILVAFLM; FIGUEIREDO JFC; FIGUEIREDO LTM; SAUAIA CC; ROMÃO E \& RODRIGUES MLV. Retinitis induction by human cytomegalovirus in imunossupressed rabbits. Medicina, Ribeirão Preto, 33: 117-122, apr./ june 2000.

ABSTRACT: The search for new therapies to the HCMV retinitis made researchers look for an animal model for this infection. In anterior study we didn't get a good level of imunossupression in rabbits with Azathiprina and Prednisona. In this way, we opt for use the Cyclophosphamide in five rabbits of New Zealand race, in which were injected HCMV in vitreous of both eyes, in different stages of imunossupression protocol. The observation period was 112 days, observing sistemics alterations (weight, blood count) and ocular alterations (trough binocular ophthalmoscopy and retinography ). After the animals sacrifice, it was researched HCMV antigens in vitreous and retina. It was found important weight loss, blood count not compatible with the imunossupression signs, retinians lesions and vitreous alterations not specifics (exsudate and vitreits with spontaneous involution ). It wasn't detected HCMV antigens in vitreous and retina inprints from the sacrificed rabbits. In this way, it was concluded that also with this new imunossupression scheme, the HCMV causes not specific intra-ocular inflamation. Therefore, the HCMV inoculation in rabbits doesn't determine an experimental model to HCMV retinitis.

UNITERMS: Cytomegalovirus Retinitis. Immunosuppression. Cyclophosphamide. Rabbits. 


\section{REFERÊNCIAS BIBLIOGRÁFICAS}

1 - ELIA LA; AIHARA T \& DIAS CRS. Alterações oculares na síndrome da imunodeficiência adquirida (AIDS ). Arq Bras Oftalmol 53:271-278, 1990.

2 - DREW WL. Cytomegalovirus infection in patients with AIDS. Clin Infect Dis 14: 608-615, 1992.

3 - SPAIDE RF; GAISSINGER A \& PODHORZER JR. Risk factors for cotton-wool spots and for cytomegalovirus retinitis in patients with human immunodeficiency virus infection. Ophthalmology 102: 1860-1864,1995.

4 - PAVÉSIO CEN; LOTTENBERG CL \& BELFORT JR R. AIDS. In : ORÉFICE F \& BELFORT JR R. Uveítes, Roca, São Paulo, cap. 35. p323-330, 1987.

5 - SPECTOR AS; MACKINLEY GF; LALEZARI JP; SAMO T; ANDRUCZK R; FOLLANSBEE S; SPARTI PD; HAVLIR DV; SIMPSON G; BUHLES W; WONG R \& STEMPIEN MJ. Oral Ganciclovir for the prevention for cytomegalovirus disease in patients with AIDS. N Engl J Med 334: 1491-1497, 1996.

6 - TATEBAYASHI M; NEYTS H; BESEN G; FLORES AGUILAR M; SMITH I; WILEY C; SPECTOR S; BERGERON-LYNN G; MAUDGALPC; CLECQ ED; GANGANPA; CHAVES E; RUSSACK $V$ \& FREEMAN WR. Absence of infectious retinitis after injection of human cytomegalovirus into rabbit eyes. $\mathrm{J}$ Infect Dis 171:782-787, 1995.

7 - DUNKEL EC; FREITAS D; SCHEER DI; SIEGEL ML; ZHU Q; WHITLEY RJ; SCHAFFER PA \& PAVAN-LANGSTON D. A rabbit model for human cytomegalovirus-induced chorioretinal disease. J Infect Dis 168: 336-344, 1993.

8 - SAUAIA CC. Observação prolongada de olhos de coelhos imunocompetentes e imunossuprimidos após inoculação intravítrea do citomegalovírus humano. Tese de Doutorado, Faculdade de Medicina de Ribeirão Preto da USP, Ribeirão Preto, p.1-43, 1998.
9 - FIGUEIREDO JFC; FIGUEIREDO LTM; SAUAIA CC; OLIVEIRA ECC; SILVA FLM \& RODRIGUES MLV. Long-term observation of normal and imunosupressed rabbits after intraocular inoculation of human cytomegalovirus (CMV). In: Abstracts, XII World Aids Conference, Geneva, June 28 - July 3, 1998.

10 - BROCK N. Pharmacologic characterization of cyclophosphamide (NSC-26271) and cyclophosphamide metabolites. Cancer Chemother Rep 409: 315-325, 1967.

11 - GREEN MT; DUNKEL EC \& LANGSTON DP. Effect of immunization and immunosuppression on induced ocular shedding and recovery of herpes simplex virus infected rabbits. Exp Eye Res 45: 375-383, 1987.

12 - LESPINE A; DOUSSET N; PERRET B; FORNI M; CHAP H \& DOUSTE-BLAZY L. Accumulation of large VLDL in cyclophosphamide treated rabbits. relationship with lipoprotein lipase deficiency. Biochem Biophys Res Commun 154: 633-640, 1998.

13 - HARUTA Y; ROOTMAN DS; XIE L; KIRITOSHI A \& HILL JM. Recurrent HSV-1 corneal lesions in rabbits induced by cyclophosphamide and dexamethasone. Invest Ophthalmol Vis Sci 30: 371-376,1989.

14 - HAWKEY CM. Comparative mammalian haematology: cellular components and blood coagulation of captive wild animals. William Heinemann Medical Books, London, 1975

15 - LAYCOCK KA; FENOGLIO ED; HOOK KK \& PEPOSE JS. A $n$ in vivo model of human cytomegalovirus retinal infection. Am J Ophthalmol 124: 181-189, 1997.

Recebido para publicação em 11/04/00

Aprovado para publicação em 16/05/00 